RMD

Open

Rheumatic \&

Musculoskeletal

Diseases
To cite: Cabrera N,

Duquesne A,

Desjonquères $\mathrm{M}$, et al.

Tocilizumab in the treatment of mixed connective tissue disease and overlap syndrome in children. $R M D$ Open 2016;2:e000271. doi:10.1136/rmdopen-2016000271

- Prepublication history for this paper is available online. To view these files please visit the journal online (http://dx.doi.org/10.1136/ rmdopen-2016-000271)

Received 26 February 2016

Revised 28 June 2016 Accepted 11 July 2016

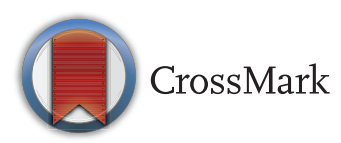

For numbered affiliations see end of article.

Correspondence to Dr Alexandre Belot; alexandre.belot@chu-lyon.fr

\title{
Tocilizumab in the treatment of mixed connective tissue disease and overlap syndrome in children
}

Natalia Cabrera, ${ }^{1}$ Agnes Duquesne, Marine Desjonquères, ${ }^{1}$ Jean-Paul Larbre ${ }^{2}$ Jean-Christophe Lega, ${ }^{3,4}$ Nicole Fabien, ${ }^{5}$ Alexandre Belot ${ }^{1,6}$

\section{ABSTRACT}

Arthritis is one of the main manifestations of mixed connective tissue disease (MCTD) and overlap syndrome in children and can be responsible for functional disability. We report on 2 children with arthritis that were dramatically improved by a treatment with interleukin-6 (IL-6) blockers in the context of connective tissue disease. However, in both cases, other systemic autoimmune symptoms were not modified by the treatment and autoantibodies tend to increase, suggesting a differential effect of IL-6 inhibition on articular inflammation and systemic autoimmunity.

\section{INTRODUCTION}

Interleukin-6 (IL-6) blockers have been reported effective in polyarticular and systemic juvenile idiopathic arthritis (JIA). ${ }^{12}$ To date, this treatment has not been reported in paediatric-onset systemic autoimmunity. Paediatric-onset mixed connective tissue disease (pMCTD) is a rare autoimmune condition with overlapping features of systemic lupus erythematosus (SLE), systemic sclerosis and polymyositis/dermatomyositis. ${ }^{3-5}$ The most common manifestations of MCTD in children are Raynaud's phenomenon and polyarthritis, in association to anti-Smith/RNP autoantibodies. ${ }^{6}$ Interestingly, antibodies to ribonucleoprotein (RNP) positivity are also predictive for arthritis in juvenile SLE and a large number of patients with MCTD fulfil the diagnosis criteria for SLE over time. ${ }^{7}$ The treatment is challenging and relies on non-steroidal anti-inflammatory drugs, corticosteroids (CTC), immunosuppressive and/or hydroxychloroquine (HCQ) ${ }^{8}$ Here, we report on two children with pMCTD with refractory arthritis who were successfully treated with tocilizumab (TCZ). However, TCZ was ineffective on systemic symptoms in both patients.

\section{Key messages \\ What is already known about this subject? \\ - In mice, IL-6 controlled induced activation of T and $B$ cells and lupus-like autoimmune reaction in various genetic background. Targeting IL-6 in human systemic autoimmunity has shown contradictory results in few case reports. \\ What does this study add? \\ - Here we report on the dual effect of tocilizumab on systemic symptoms in the context of pediat- ric-onset mixed connectivitis. Refractory arthritis was very sensitive to IL-6 blockade, while the other lupus-like systemic symptoms were not modified and even possibly increased. \\ How might this impact on clinical practice? \\ - In the context of systemic autoimmunity, treat- ing arthritis is sometimes challenging. II-6 blockers may represent a promising option but a cautious follow-up of other systemic manifesta- tions and autoantibodies is mandatory.}

\section{CASE REPORTS}

A 7-year-old girl (patient 1) was diagnosed for rheumatoid factor-negative polyarticular JIA (according to the International League against Rheumatism criteria) and maintained under remission with methotrexate (MTX) and etanercept. At the age of 15 years, she presented with a polyarticular relapse concomitant with the appearance of Raynaud's phenomenon and puffy hands (figure 1A). She fulfilled the Kasukawa criteria for MCTD diagnosis with consistent laboratory examinations (table 1). Since the major symptoms were non-erosive polyarthritis and swollen hands (figure 1B) and in the context of positive autoantibodies, TCZ ( $8 \mathrm{mg} / \mathrm{kg} / 4$ weeks) was initiated and etanercept was discontinued. Articular outcome was quickly favourable with a complete remission after the fifth infusion (figure 1C). Under TCZ, antiglobulin test and cryoglobulinemia became positive and the level of double- 
A

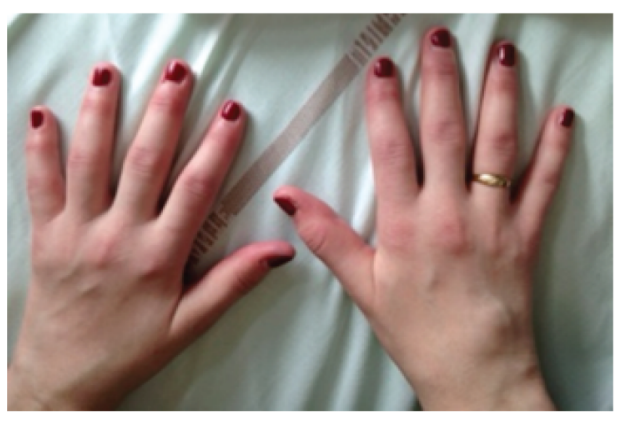

B

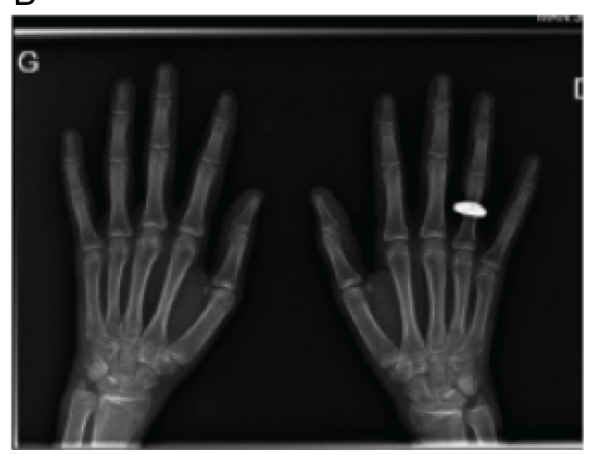

C

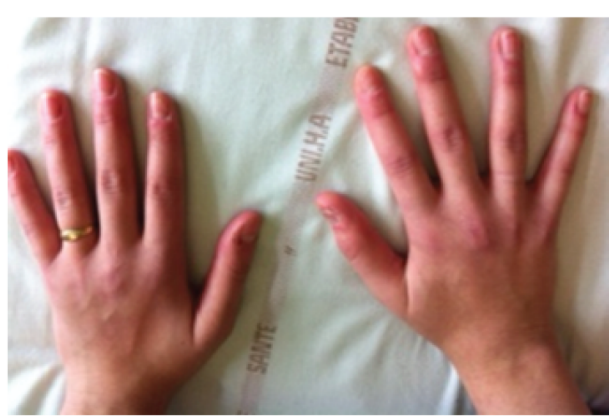

Figure 1 Hand arthritis and swollen hands. (A) Polyarticular relapse, aspect of puffy hands, wedged ring because arthritis/ oedema. (B) X-ray of the hands: no articular erosions. (C) After fifth tocilizumab infusion, reduction of oedema and arthritis, ring can be removed and interchanged.

stranded DNA (dsDNA) autoantibodies was raised (table 1). Her treatment also included low-dose stable steroids and HCQ.

A 12-year-old girl (patient 2) diagnosed for a juvenile dermatomyositis was successfully treated with steroids and MTX. She relapsed 2 years later with spreading symptoms including Raynaud's phenomenon, sclerodactyly, hepatitis and polyarthritis, followed 1 year later by Sicca syndrome with positive autoantibodies (table 1), overlap syndrome was considered. Several drug regimens were subsequently introduced but remained ineffective on polyarthritis. A treatment with TCZ $(8 \mathrm{mg} / \mathrm{kg}$ for 4 weeks) together with MTX was initiated at the age of 17 years, due to a new joint relapse. This treatment was shortly effective on joint manifestations and CTC were significantly tapered $(5 \mathrm{mg} /$ day). Other manifestations such as Raynaud's phenomenon and intermittent liver cytolysis remained unmodified (table 1).

\section{DISCUSSION}

TCZ is a humanised monoclonal antibody that targets the IL-6 receptor (IL-6R). It is approved in the treatment of polyarticular or systemic-onset JIA in Europe and North America and has been approved for Castleman's disease in Japan. ${ }^{45}$ In JIA there is a positive correlation between circulating IL-6 levels and the severity of joint damage. ${ }^{5}$ Patient 1 had fulfilled the diagnostic criteria for MCTD. Patient 2 had an overlap syndrome encompassing juvenile dermatomyositis, systemic sclerosis and SLE. In both cases, TCZ was effective in the treatment of arthritis. In contrast, TCZ has been reported with contradictory results in adult-onset SLE with single case reports displaying either improvement or flare under treatment. ${ }^{9}{ }^{10}$ Interestingly, arthritis seems highly sensitive to IL-6 blockers in this context while systemic symptoms seem less sensitive to TCZ. In a small open study of TCZ in adult-onset SLE, patients presented with leucopenia and a decrease of complement fraction. ${ }^{11}$ Here, our patients maintained or developed autoantibodies under treatment suggesting that IL-6 blockers are not efficient on such systemic manifestations. In patient 1 systemic autoantibodies increased under TCZ treatment with a higher anti-dsDNA antibodies level, an effect that has been already reported with tumour necrosis factor inhibitors. ${ }^{12}$ For patient 2, TCZ had no effect on extra-articular manifestations such as hepatitis. These observations are intriguing and suggest that in the context of pMCTD, IL- 6 might be beneficial to prevent systemic autoimmunity. Although most soluble cytokine receptors are antagonists and compete with their membrane-associated counterparts for the soluble ligand, soluble IL-6Rs are capable to transmit signals by interacting with the ubiquitously expressed membrane-bound $\beta$-receptor glycoprotein (gp) gp130 on IL-6R negative cells. This latter interaction is called alternative, and in this situation IL-6/ IL-6R complex have been shown to play protective function, especially in some cases of acute crescentic 
Table 1 Clinical and laboratory features of patients before and after TCZ

\begin{tabular}{|c|c|c|c|c|c|}
\hline \multirow[b]{2}{*}{$\begin{array}{l}\text { M0 (previous treatment) } \\
\text { NSAID, steroids, } \\
\text { methotrexate, } \\
\text { hydroxychloroquine, } \\
\text { etanercept, } \\
\text { adalimumab }\end{array}$} & M6 & M12 & \multirow[b]{2}{*}{$\begin{array}{l}\text { M0 (previous treatment) } \\
\text { NSAID, steroids, } \\
\text { methotrexate, } \\
\text { hydroxychloroquine, } \\
\text { mycophenolate } \\
\text { mofetil, etanercept }\end{array}$} & M6 & M12 \\
\hline & \multicolumn{2}{|c|}{$\begin{array}{l}\text { TCZ, steroids (low dose at } \\
5 \mathrm{mg} / \text { day), } \\
\text { hydroxycholoroquine }\end{array}$} & & \multicolumn{2}{|c|}{$\begin{array}{l}\text { TCZ, steroids (low } \\
\text { dose at } 5 \mathrm{mg} / \text { day), } \\
\text { hydroxychloroquin, } \\
\text { methotrexate }\end{array}$} \\
\hline 15 & 16 & 17 & 15 & 15 & 16 \\
\hline 20 & 0 & 0 & 14 & 1 & 0 \\
\hline+ & + & + & + & + & + \\
\hline 129 & 115 & 119 & 125 & 116 & 135 \\
\hline 5.04 & 3.14 & 2.3 & 6.17 & 7.5 & 7.17 \\
\hline 2.36 & 1.35 & 1.15 & 1.79 & 2.3 & 1.51 \\
\hline 369 & 290 & 229 & 400 & 394 & 262 \\
\hline 36.2 & $<0.2$ & $<0.2$ & 18.6 & $<0.2$ & $<0.2$ \\
\hline 31 & 24 & 28 & 101 & 145 & $<40$ \\
\hline \multirow[t]{2}{*}{13} & 17 & 25 & 88 & 326 & $<40$ \\
\hline & & & 1292 & 98 & 80 \\
\hline $1 / 1600$ & $1 / 1280$ & $1 / 1280$ & $1 / 1600$ & $1 / 1280$ & $1 / 128 C$ \\
\hline 30 & 85 & $>97$ & 7.4 & 7.1 & 7 \\
\hline- & - & - & $>2$ & $>2$ & 3.7 \\
\hline$>8$ & 4 & & $>2$ & $>2$ & $>8$ \\
\hline- & + (type III) & + (type III) & - & - & - \\
\hline
\end{tabular}

\section{TCZ treatment}

Age (years)

Joint manifestation (cJADAS)*

Raynaud's phenomenon

Haematology

$\mathrm{Hb}(\mathrm{g} / \mathrm{L})$

WCC $(\mathrm{g} / \mathrm{L})$

Lymphocytes $(g / L)$

Platelet

Biochemistry

CRP $(<5 \mathrm{mg} / \mathrm{L})$

ASAT $(<40 \mathrm{U} / \mathrm{L})$

ALAT $(<40 \mathrm{U} / \mathrm{L})$

CK (<200 U/L)

Immunology

ANA

dsDNA Ab RIA (Farr assay $>7 \mathrm{UI} / \mathrm{mL}$ )

Anti-SSA $60 \mathrm{kDa}$

Anti-U1RNP

Cryoglobulinaemia
-8.5 , high disease activity $>8.5$.

( inmatory drugs; RIA, radioimmunoassay; SSA, anti-Sjogren's-syndrome-related antigen TCZ, tocilizumab; Anti-U1 RNP, Anti-U1 small nuclear ribonucleoprotein; WCC, white cell count. 
glomerulonephritis. ${ }^{13}{ }^{14}$ One can speculate that this alternative pathway of cell activation can be beneficial in the context of systemic autoimmunity and that IL-6 inhibition alleviates part of this protective action. However, articular involvement was dramatically improved by TCZ illustrating that IL- 6 might play a differential role in local inflammation and autoimmunity.

These two observations suggest that TCZ may be effective to treat joint manifestations in the context of MCTD/overlap syndrome but systemic autoimmunity does not seem to be prevented. DsDNA antibodies may appear or increase over time and a cautious follow-up of autoantibodies and autoimmune manifestations is mandatory in the setting of TCZ treatment in systemic autoimmune diseases.

\section{Author affiliations}

${ }^{1}$ Department of Pediatric Rheumatology, Hôpital Femme Mère Enfant, Hospices Civils de Lyon, Claude Bernard University Lyon 1, University of Lyon, Lyon, France

${ }^{2}$ Department of Rheumatology, Centre Hospitalier Lyon Sud, Hospices Civils de Lyon, Claude Bernard University Lyon 1, University of Lyon, Pierre-Bénite, France

${ }^{3}$ Department of Internal and Vascular Medicine, Centre Hospitalier Lyon Sud, Hospices Civils de Lyon, Claude Bernard University Lyon 1, University of Lyon, Lyon, France

${ }^{4}$ Laboratoire de Biométrie et Biologie Evolutive, CNRS, Claude Bernard University Lyon 1, University of Lyon, Lyon, France

${ }^{5}$ Department of Immunology, Centre Hospitalier Lyon Sud, Hospices Civils de Lyon, Lyon, France

${ }^{6}$ INSERM U1111

Contributors NC collected data, wrote the initial draft of the study, drafted the initial manuscript; AD, MD, J-PL and J-CL helped writing the clinical data and took care of the two children. They critically reviewed the initial draft. NF collected sera for each patient and analysed the autoimmune profile; $A B$ designed the project, reviewed and revised the manuscript, and approved the final manuscript as submitted; all authors approved the final manuscript as submitted and agree to be accountable for all aspects of the work.

Competing interests None declared.

Patient consent Obtained.

Provenance and peer review Not commissioned; externally peer reviewed.

Data sharing statement No additional data are available.
Open Access This is an Open Access article distributed in accordance with the Creative Commons Attribution Non Commercial (CC BY-NC 4.0) license, which permits others to distribute, remix, adapt, build upon this work noncommercially, and license their derivative works on different terms, provided the original work is properly cited and the use is non-commercial. See: http:// creativecommons.org/licenses/by-nc/4.0/

\section{REFERENCES}

1. Brunner HI, Ruperto N, Zuber Z, et al. Efficacy and safety of tocilizumab in patients with polyarticular-course juvenile idiopathic arthritis: results from a phase 3 , randomised, double-blind withdrawal trial. Ann Rheum Dis 2015:74:1110-17.

2. De Benedetti F, Brunner HI, Ruperto N, et al. Randomized trial of tocilizumab in systemic juvenile idiopathic arthritis. N Engl J Med 2012;367:2385-95.

3. Ortega-Hernandez OD, Shoenfeld Y. Mixed connective tissue disease: an overview of clinical manifestations, diagnosis and treatment. Best Pract Res Clin Rheumatol 2012;26:61-72.

4. Tani C, Carli L, Vagnani S, et al. The diagnosis and classification of mixed connective tissue disease. J Autoimmun 2014;48-49:46-9.

5. van den Hoogen F, Khanna D, Fransen J, et al. 2013 classification criteria for systemic sclerosis: an American College of

Rheumatology/European League Against Rheumatism collaborative initiative: ACR/EULAR classification criteria for SSc. Arthritis Rheum 2013;65:2737-47.

6. Tellier S, Bader-Meunier B, Quartier P, et al. Initial presentation and outcome of pediatric-onset mixed connective tissue disease: a French multicenter retrospective study. Joint Bone Spine 2016;83:369-71.

7. Sule SD, Moodalbail DG, Burnham J, et al. Predictors of arthritis in pediatric patients with lupus. Pediatr Rheumatol Online $J$ 2015;13:30.

8. Tsai YY, Yang $\mathrm{YH}, \mathrm{Yu} \mathrm{HH}$, et al. Fifteen-year experience of pediatric-onset mixed connective tissue disease. Clin Rheumatol 2009;29:53-8.

9. Jüptner M, Zeuner R, Schreiber S, et al. Successful application of belimumab in two patients with systemic lupus erythematosus experiencing a flare during tocilizumab treatment. Lupus 2014;23:428-30.

10. Maeshima K, Ishii K, Torigoe M, et al. Successful tocilizumab and tacrolimus treatment in a patient with rheumatoid arthritis complicated by systemic lupus erythematosus. Lupus 2012;21:1003-6.

11. Illei GG, Shirota $\mathrm{Y}$, Yarboro $\mathrm{CH}$, et al. Tocilizumab in systemic lupus erythematosus-safety, preliminary efficacy, and impact on circulating plasma cells. Arthritis Rheum 2010;62:542-52.

12. Adler S, Kolev M, Varisco PA, et al. Induction of severe systemic lupus erythematosus by TNF blockade and response to anti-IL-6 strategy. J Allergy Clin Immunol 2013;131:1235-7.e1.

13. Luig M, Kluger MA, Goerke B, et al. Inflammation-Induced IL-6 Functions as a Natural Brake on Macrophages and Limits GN. J Am Soc Nephrol 2015;26:1597-607.

14. Braun GS, Nagayama $Y$, Maruta $Y$, et al. IL-6 Trans-Signaling Drives Murine Crescentic GN. J Am Soc Nephrol 2016;27:132-42. 